\title{
Can We Trust the Quality of Generic Drugs?
}

\author{
Katherine Eban
}

\section{Eban's Viewpoint}

$\Lambda$ s elected officials, consumer organizations and health care providers and managers battle over prescription drug prices, questions of drug quality have received much less attention. In fact, a single premise seems to unify our drug supply: Once the U.S. Food and Drug Administration (FDA) approves a drug, it is safe and effective to use. For generics, FDA approval means that a drug is not only safe and effective but also bioequivalent and therefore interchangeable with the brand and other available versions. But in 2008, I got a surprising phone call—one that would lead me into a transcontinental reporting journey and to fundamental questions about the FDA's ability to fulfill its mission to ensure the integrity of all the drugs that it approves.

That 2008 phone call came from Joe Graedon, a trained pharmacologist and cohost of the NPR radio program The People's Pharmacy. I had previously been a guest on Graedon's show to discuss my work reporting on the pharmaceutical industry. But this time, he was calling to ask for my help. He said that he had been flooded with calls from patients who had been switched to generic drugs and were experiencing terrible side effects. Graedon brought these complaints to the FDA, but officials there told him the reactions were likely psychosomatic, caused by differences in shape or color of the generic medication. Graedon suspected there was some deeper problem, and he posed a question to me: "What is wrong with the drugs?"

At that point, I had been an investigative journalist for over a decade. I frequently got tips from sources who wanted to highlight problems or expose wrongdoing. Writing for publications such as The New York Times and Vanity Fair, I had developed a good sense for which tips might be worth pursuing. Graedon had long advocated that consumers deserved access to low-cost medicine. He had been on the side of generics, with no other agenda than to ensure patient welfare. In short, his tip seemed credible, albeit surprising.

Joe Graedon's question propelled me into a 10-year journey across 4 continents and deep into the executive suites of distant generic drug companies. My reporting, which relied on hundreds of interviews, over 20,000 confidential FDA documents, and internal records from numerous corporate whistleblowers, led me inexorably to the troubling conclusion that data fraud

J Manag Care Spec Pharm. 2020;26(5):589-91

Copyright $\odot 2020$, Academy of Managed Care Pharmacy. All rights reserved. is endemic at the overseas plants producing the majority of America's generic drugs and that the FDA, with its short-staffed and credulous foreign inspection system, was ill-equipped to tackle it. As a result, I came to question whether the generic drugs being approved by the FDA really were uniformly bioequivalent, as widely assumed.

In 2008, I began where Graedon had pointed me, with the patients and doctors. Those who had become skeptical of generics were not hard to find. Patients described medical odysseys in which they ping-ponged between specialists as they pursued worrying symptoms, only to realize that a medication change had sparked their crisis. Doctors, particularly those who prescribed narrow therapeutic index drugs, expressed concern. They described previously stabilized patients who relapsed after a medication change. As the head of the American Psychiatric Association told me, "The FDA says it's satisfied. My question is, are we satisfied?"

In 2009, my first article raising questions about generic drug quality appeared in Self magazine. Based on close to 50 interviews, the article was the first account of these problems in a mainstream publication and closely examined the FDA's system for approving generic drugs-its reliance on company data, its lack of systematic drug testing, and the rather wide range in the FDA's bioequivalence standard. But I still could not answer Joe Graedon's underlying question: What was wrong with the drugs?

\section{Corporate Corruption and the Race for Profits}

I might never have answered that question, but a month after that article came out, someone calling himself "Four Dollar Refill" emailed me anonymously. That person worked in the generic drug industry, and as we got into dialogue, he suggested that I examine the overseas manufacturing plants, primarily in India and China, where the majority of our generic drugs are made. That reoriented my reporting. Although I did not know it yet, I was on the outskirts of a profound story: one that involved corporate corruption, the race for profits, grave risks to public health, and the challenges facing regulators in a globalized world.

That story began with the account of 1 company, RanbaxyIndia's largest drug manufacturer-and ultimately expanded to encompass the generic drug industry more broadly. Through government and pharmaceutical industry sources, I learned that Ranbaxy was facing a sprawling Justice Department investigation for fabricating its quality data. Documents from 
a whistleblower had triggered the probe. Over the next several years, I was able to piece together the story of how Ranbaxy's new research and development director, Dr. Raj Kumar, who had been recruited from GlaxoSmithKline, came to fear that Ranbaxy was systematically falsifying its data in applications to global regulators. He commissioned a subordinate named Dinesh Thakur to review Ranbaxy's global regulatory filings and to determine what data was real or fake.

Thakur's findings were devastating. Ranbaxy had falsified data for over 200 drug products in more than 40 countries. The company's scientists had secretly altered ingredients to try and get better results. The company tested brand-name drugs and used those results in applications as if the data had come from tests of its own drugs. In short, it used every imaginable subterfuge to speed drug approvals and increase profits, a scheme that jeopardized the health of patients around the world.

In October 2004, Dr. Kumar presented Thakur's findings to a subcommittee of the board of directors. He recommended that the company pull every affected drug from global markets and retest them. But the board opted for a coverup instead. It asked Kumar to destroy Thakur's report and the computer on which it was created. Kumar resigned and Thakur was then forced out of the company. By August 2005, Thakur had decided to blow the whistle. He brought his information and documents to the FDA, which launched an investigation. Eight years later, in May 2013, the company pled guilty to 7 felonies related to falsifying data.

In May 2013, my 10,000-word article about Ranbaxy's crimes, and Thakur's journey to expose them, ran on Fortune magazine's website. ${ }^{1}$ But after 5 years of reporting, I still had unanswered questions. Yes, I knew what was wrong with Ranbaxy's drugs. But the complaints Graedon received from patients were not just about Ranbaxy's drugs; they involved drugs from numerous different manufacturers. This led me to an obvious next question: was Ranbaxy an outlier or the tip of the iceberg? A number of whistleblowers from other generic drug companies, and from inside the FDA, helped me answer that question, as I pieced together the larger story of an industry riddled with fraud.

There was the Indian drug company Wockhardt, which had released to patients in the Middle East vials of insulin that contained metallic fragments from corroded equipment. Wockhardt was secretly making a cardiac drug for the U.S. market, adenosine, on that same equipment and tried to conceal evidence by smuggling records from the plant during an FDA inspection. ${ }^{2}$ In China, at a plant run by Zheijang Huahai, the company was ignoring impurity spikes in its own drugs. Although in 2017 an FDA inspector caught this and recommended that the FDA designate the plant with its most serious finding, Official Action Indicated, the FDA downgraded its inspectional finding to Voluntary Action Indicated, essentially allowing the plant to continue business as usual. ${ }^{3}$ Within a year, that plant was in the middle of a worldwide regulatory crisis when its active ingredient was found to contain the carcinogen N-Nitrosodimethylamine (NDMA).

The FDA's warning letters and import alerts from overseas plants typically appear as blips on the public radar. But as I delved into them, I saw they revealed patterns of conduct aimed at the deliberate manufacturing of substandard drugs as a way to increase profits. After my Fortune article ran, an FDA consultant contacted me, comparing what she called "fast drugs" to "fast fashion." American consumers buy cheap clothing at retail chains, with the understanding that the garments are likely made in overseas plants with cheap labor, manufacturing shortcuts, and suboptimal worker conditions. But when it comes to their clothing, American consumers accept these tradeoffs in order to pay less.

The same held true for our low-cost drugs, the consultant posited. They were being manufactured in what amounted to pharmaceutical sweatshops-overseas drug plants that were taking perilous shortcuts with the veracity of their data, the sterility of their facilities, and a host of other required standards. Consumers had little understanding of that, she explained, because the FDA had essentially assured us that the generics it approved were a bargain with no downside. But that was not true, as some of the FDA's own investigators were learning firsthand.

\section{Facade of Compliance Overseas}

One glaring problem is the FDA's system of overseas inspections. The FDA notifies foreign drug plants sometimes months in advance when its investigators will be arriving, which allows the plants to create a façade of compliance, all the while working to conceal shortcuts from regulators. A report issued by the Government Accountability Office in December 2019 noted that this system of preannounced inspections allows manufacturers to fix problems in advance, "raising questions about the equivalence of foreign to domestic inspections," as the report stated. ${ }^{4}$

In my book Bottle of Lies, ${ }^{5}$ I detail the revelatory inspections of the FDA investigator Peter Baker, who used unique methods to uncover the truth inside foreign drug plants. Instead of asking the plants for printouts of data, he looked directly inside the computer systems. There, he found extensive evidence that plants were secretly pretesting their drugs to forecast the results, then deleting those pretests and keeping only manipulated results, which showed that the drugs fell within specifications.

From 2012 to 2016, Baker inspected 86 plants in India and China and found evidence of fraud in four fifths of them (a complete list of Peter Baker's inspections and those of all FDA inspectors may be found at: https://fdazilla.com). Baker ultimately concluded that many of the drugs were not sufficiently safe to take: "[If people actually understood] then no one would take [these drugs]." 
What does all of this mean for patients? It is hard to say exactly, since there are few studies measuring the actual impact. Are they relapsing, becoming unstable, or getting rehospitalized after medication switches? Do our generics come with a hidden cost? At least anecdotally, the answer appears to be "yes."

In 2013, pharmacists at Cleveland Clinic grew so concerned about the quality of generic drugs made by the Indian company Dr. Reddy's Laboratories that they stopped purchasing the company's immunosuppressant, tacrolimus, and removed it from the hospital system's formulary and in-house pharmacies. Their concern proved prescient. Several heart transplant patients who were recovering nicely were subsequently discharged from the Cleveland Clinic, only to wind back up at the emergency room and in intensive care after being switched at their local pharmacies to the Dr. Reddy's version of tacrolimus.

As it turned out, the pharmacists at Cleveland Clinic were not alone in their concerns. In October 2013, a pharmacist at the Loma Linda University Medical Center in California reported to the FDA, through its online complaint database Medwatch, that "multiple patients" who used the Dr. Reddy's tacrolimus had "unpredictable levels leading to inadequate immunosuppression and subsequent transplant failure." The report from Loma Linda noted, "This has only been seen with the Dr. Reddy's brand of Prograf."

It is not clear how the FDA responded to Loma Linda's report at the time. But in January 2020, 7 years after Loma Linda first alerted the FDA of its concerns and 8 months after I first publicized the concerns with generic tacrolimus in Bottle of Lies, the agency quietly noted in a quarterly report that it was investigating the problem of "therapeutic inequivalence" with generic versions of tacrolimus. ${ }^{7}$

\section{The Need for Real Verification}

The underlying assumption of our drug supply-that if the FDA approves a drug it is safe to take-is being tested like never before. With the widespread and ongoing recalls of angiotensin receptor blockers that have been found to contain NDMA, the disclosures in my book Bottle of Lies, and congressional hearings that are exposing the threadbare nature of the FDA's overseas inspection system, is it time to reconsider that assumption?

What would a drug supply chain look like in which participants no longer took that for granted? Pharmacies would test the drugs they dispense, a model pioneered by the small Connecticut pharmacy Valisure. Physicians and pharmacists would consider the possibility of poor drug quality when the status of a previously well-managed patient abruptly changed. Prescription drug formulary managers would not simply seek the cheapest drugs available but would heed the concerns raised in FDA inspection reports and warning letters in determining approved sources for covered medications. The FDA would make surprise inspections and systematic testing a mandatory part of its approval process and not downgrade the sanctions recommended by its own investigators.
We know more disclosures are coming. Since I published Bottle of Lies, dozens more whistleblowers have contacted me. The Government Accountability Office continues to probe the FDA's downgrading of inspectional findings that I first exposed in my book. It is up to responsible actors in our health care system to consider whether the assumption of the FDA's infallibility should be replaced with a system of real verifications. That system should include unannounced inspections, systematic testing, and heavy penalties for violators. For those making formulary decisions, it is time to look beyond the lowest cost and figure out how to reliably assess quality so that the generic medicines Americans rely on truly have no downside.

\section{Authors}

KATHERINE EBAN is an investigative journalist, Andrew Carnegie Fellow, and author of Bottle of Lies: The Inside Story of the Generic Drug Boom.

AUTHOR CORRESPONDENCE: Katherine Eban can be contacted at https://www.katherineeban.com/.

\section{DISCLOSURES}

No funding was provided for the writing of this article. The author has nothing to disclose.

\section{REFERENCES}

1. Eban K. Dirty medicine. Fortune. May 15, 2013. Available at: https://fortune.com/2013/05/15/dirty-medicine/. Accessed March 25, 2020.

2. U.S. Food and Drug Administration. Establishment inspection report, Wockhardt Ltd. Aurangabad, India, March 18-22, 2013.

3. Tamara Felton Clark, Branch Chief, Global Compliance Branch 4. Pharmaceutical Reclassification of surveillance inspection: VAI as inspection classification. Work Activity 161861. Zheijiang Huahai Pharmaceutical Co., Ltd. (FEI \#3003885745). September 7, 2017.

4. U.S. Government Accountability Office. Testimony before the Subcommittee on Oversight. and Investigations, Committee on Energy and Commerce, House of Representatives. Drug safety: preliminary findings indicate persistent challenges with FDA foreign inspections. Statement of Mary Denigan-Macauley, Director, Health Care. GAO-20-262T. December 10, 2019. Available at: https://www.gao.gov/assets/710/703078.pdf. Accessed March 25, 2020

5. Eban K. Bottle of Lies: The Inside Story of the Generic Drug Boom. New York: HarperCollins Publishers; 2019.

6. Eban K. These pills could kill you. Updated May 24, 2019. Available at: https://www.bostonglobe.com/ideas/2019/05/24/ideas-katherine-eban-thesepills-could-kill-you/d4gYXkoMR24nluoLUkbnqJ/story.html. Accessed April 13, 2020.

7. U.S. Food and Drug Administration. Potential signals of serious risks/new safety information identified by the FDA Adverse Event Reporting System (FAERS). Quarterly reports July-September 2019. Available at: https://www. fda.gov/drugs/questions-and-answers-fdas-adverse-event-reporting-systemfaers/potential-signals-serious-risksnew-safety-information-identified-fdaadverse-event-reporting-system. Accessed March 25, 2020. 